\title{
Capacidade Absortiva: Um Estudo na Indústria Criativa
}

\author{
Absorptive Capacity: A Study in the Creative Industry
}

\author{
Chrístian Langaro Vaisz ${ }^{1}$ \\ Maria Cristina Bohnenberger ${ }^{2}$ \\ Serje Schmidt ${ }^{3}$ \\ Dusan Schreiber ${ }^{4}$
}

\begin{abstract}
Resumo
O contexto dinâmico das evoluções tecnológicas e suas implicações, tanto sociais quanto mercadológicas, se apresentam como um desafio constante para as empresas. Essa realidade é também vivenciada pela indústria criativa caracterizada, entre outros aspectos, pela constante inovação, criatividade e alta dependência do conhecimento dos indivíduos nela inseridos. A capacidade absortiva de uma organização, que consiste na aquisição, assimilação, transformação e exploração de conhecimentos externos, gera oportunidades para a empresa inovar e manter-se sustentável em um ambiente competitivo. A partir dessas premissas, este artigo tem como objetivo analisar o uso da capacidade absortiva no processo de diversificação de atividades de uma pequena empresa inserida na indústria criativa. Os resultados mostram que cada uma das dimensões da capacidade absortiva foi importante para que houvesse uma diversificação das atividades desenvolvidas pela empresa, impactando tanto na organização interna quanto nas relações que a empresa mantém com o mercado, o que foi possível por meio da formação de relações de aprendizagem interorganizacionais.
\end{abstract}

Palavras-chave: capacidade absortiva; aprendizagem organizacional; indústria criativa; estudo de caso; estratégia.

\begin{abstract}
The dynamic context of technological developments and their implications, both social and market, present themselves as a constant challenge for companies. This reality is also experienced by the creative industry characterized, among other aspects, by constant innovation, creativity, and high dependence on the knowledge of the individuals inserted in it. The absorptive capacity of an organization, which consists of the acquisition, assimilation, transformation, and exploitation of external knowledge, creates opportunities for the company to innovate and remain sustainable in a competitive environment. Based on these premises, this article aims to analyze the use of absorptive capacity in the process of diversifying activities of a small company inserted in the creative industry. The results show that each of the dimensions of the absorptive capacity was important for there to be a diversification of the activities developed by the company, impacting both the internal organization and the relations that the company maintains with the market, which was possible through the formation of relationships interorganizational learning.
\end{abstract}

Keywords: absorptive capacity. organizational learning. creative industry. case study. strategy.

19 Mestre em Indústria Criativa pela Universidade FEEVALE.

20 Doutora pela Universidade das Ilhas Baleares - Espanha. Professora e Pesquisadora do Mestrado em Administração e Mestrado Profissional em Indústria Criativa, da Universidade FEEVALE.

Doutor em Economía de Lempresa pela Universitat de Les Illes Balears, Espanha e em Administração pela UNISINOS. Professor e Pesquisador do Mestrado em Administração e Mestrado Profissional em Indústria Criativa, da Universidade FEEVALE. Programa em Qualidade Ambiental da Universidade FEEVALE. 


\section{INTRODUÇÃO}

Em um ambiente dinâmico, no qual as evoluções tecnológicas têm implicações tanto sociais quanto mercadológicas, é fundamental que uma organização saiba capturar conhecimentos externos e aproveitá-los em seus modelos de negócio para buscar sua sustentabilidade. A flexibilização de processos e negócios também requer certo nível de aprendizagem para a empresa e para as pessoas que fazem parte dela. Nesse ambiente, a contribuição da capacidade absortiva, ou seja, a capacidade de perceber, assimilar e aplicar os conhecimentos externos, juntamente com a expertise prévia, torna-se relevante (COHEN; LEVINTHAL, 1990; ZAHRA; GEORGE, 2002).

Esse contexto dinâmico também se apresenta como um desafio constante para as empresas pertencentes à indústria criativa. Throsby (2001) define as indústrias criativas por meio de um modelo que advém da distinção de valor cultural e valor econômico. Para o autor, "o conteúdo econômico deste modelo está representado no valor de mercado e não mercado dos bens e serviços produzidos assim como produtos intermediários e finais nas várias camadas do sistema" (2010, p. 91, tradução nossa). Para Hartley et al. (2013), as indústrias criativas desenvolvem novos conteúdos e aplicações utilizando novas tecnologias de forma experimental. Em contraste com as classificações estáticas, propõe-se uma conexão das indústrias criativas com processos fundamentais de inovação em uma economia que evolui. Há um engajamento na coordenação dessas novas tecnologias para novos estilos de vida e significados, tornando-se a base para novas oportunidades de negócio.

É importante destacar que não há um consenso sobre a definição das atividades e empresas que compõe o setor da indústria criativa, pois elas variam entre os países. No Brasil, a classificação da Federação das Indústrias do Estado do Rio de Janeiro (Firjan) é a mais utilizada, sendo composta por treze áreas: publicidade, arquitetura, design, moda, expressões culturais, patrimônio e artes, música, artes cênicas, editorial, audiovisual, P\&D, biotecnologia e tecnologia da informação e comunicação (FIRJAN, 2016). Nessa indústria, em que os bens simbólicos e valores culturais se relacionam com os valores econômicos, a criatividade pode ser considerada como um insumo necessário para a sustentabilidade organizacional. Alguns autores consideram o conhecimento um pré-requisito para aumentar o potencial criativo de um indivíduo (AMABILE, 1998; STERNBERG, 2006). Nesse sentido, a capacidade de adquirir conhecimentos também representa vantagem competitiva para empresas da indústria criativa.

Pesquisas realizadas com pequenas e médias empresas da indústria criativa evidenciam a relação positiva entre capacidade absortiva e desempenho em inovação. Esses estudos consideraram empresas localizadas na Romênia (POPESCU et al, 2019), na Itália (SANTORO, BRESCIANI e PAPA, 2020), na Indonésia (KURNIAWAN et al, 2020) e, especificamente, em Java Central (SULISTYO e WIKANINGRUM, 2019). Os referidos autores utilizaram metodologias quantitativas, coletando dados de várias empresas nas suas respectivas regiões, testando hipóteses previamente formuladas. Embora relevantes e abrangentes, esses estudos carecem de aprofundamento no que se refere a como esses processos acontecem no dia a dia das empresas, levando em consideração as especificidades das áreas da indústria criativa. No tocante aos exemplos com empresas brasileiras, Buss et al. (2019) apresentam a relação entre a capacidade absortiva e o processo criativo em um estudo de caso em três agências de publicidade do Sul do Brasil, enquanto Duarte, Castro e Borges (2018) abordam a capacidade absortiva na transferência de conhecimento de uma empresa para sua filial em outro país. Dessa forma, ainda permanecem escassas as evidências qualitativas relacionadas à capacidade de absorver conhecimentos externos e sua aplicação em novas oportunidades de negócio.

Para contribuir nesse campo de conhecimento, este artigo tem como objetivo analisar o uso da capacidade absortiva no transcorrer de um processo de diversificação das atividades em uma empresa produtora de áudio para cinema, séries de televisão e jogos digitais. Esse processo de diversificação ocorreu a partir de 2015, quando a empresa $X$ passou a fornecer serviços de dublagens em português para jogos digitais estrangeiros. Para atingir esse objetivo, foi conduzido um estudo de caso único utilizando entrevistas semiestruturadas, observação participante e análise documental (YIN, 2005).

O artigo está estruturado em seis seções: a primeira seção contextualiza o tema e apresenta o objetivo de pesquisa; a segunda seção aborda conceitualmente a capacidade absortiva e sua relação com a aprendizagem organizacional; a terceira seção apresenta a empresa que foi o objeto deste estudo; a quarta seção apresenta a metodologia utilizada; a quinta descreve os resultados da pesquisa; e, por fim, a sexta seção contempla as considerações finais.

\section{CAPACIDADE ABSORTIVA}

O termo capacidade absortiva começou a ser utilizado a partir do estudo de Cohen e Levinthal (1990). Os autores conceituam o termo como a capacidade de uma organização reconhecer o valor de novas informações externas, assimilar e aplicar essas informações para incrementar sua capacidade de inovar. Nesse sentido, a capacidade absortiva está diretamente relacionada com a aprendizagem. Cohen e Levinthal (1990) também argumentam que a capacidade de avaliar e utilizar o conhecimento externo está fundamentalmente relacionada ao nível de conhecimentos prévios pertencentes à organização. Esses conhecimentos já adquiridos consistem em saberes e processos de um 
determinado campo que concedem a habilidade de reconhecer os valores de novos conhecimentos, assimilá-los e aplicá-los em fins comerciais, constituindo assim as três etapas da capacidade absortiva. Entretanto os autores argumentam que, para desenvolver uma capacidade absortiva efetiva, não basta expor brevemente os indivíduos a conhecimentos anteriores, pois a intensidade do esforço é fundamental nesse processo.

Cohen e Levinthal (1990) também salientam que a capacidade absortiva de uma empresa não consiste na soma das capacidades dos indivíduos que a ela pertencem. Os autores ressaltam a importância de considerar quais aspectos da capacidade absortiva são especificamente organizacionais. Portanto, o modelo criado por Cohen e Levinthal (1990) leva em consideração a estrutura de comunicação entre o ambiente externo e a organização, estendendo aos seus departamentos, bem como as características e distribuição de expertise dentro da organização.

Após esse importante estudo, que serviu como ponto de partida, outros autores apresentaram complementaridades e contrapontos ao conceito, tais como Zahra e George (2002), Jansen et al (2005), Flatten et al (2011), Silva et al (2016) . Zahra e George (2002), propondo que a capacidade absortiva é formada por quatro capacidades organizacionais, construídas umas sobre as outras para produzir uma capacidade dinâmica que impulsiona a habilidade de criar e implantar novos conhecimentos para outras áreas da empresa. Essas capacidades são denominadas como aquisição, assimilação, transformação e exploração. As quatro dimensões compõem dois subconjuntos de capacidade absortiva, que os autores definem como a capacidade potencial e a capacidade realizada. Dada a importância desses conceitos para esta pesquisa, faz-se necessário um detalhamento das dimensões propostas por Zahra e George (2002).

A dimensão da aquisição é o processo em que a empresa identifica e adquire conhecimento gerado externamente. Também são utilizados conhecimentos e investimentos anteriores. Além disso, o processo de aquisição possui três atributos que auxiliam na capacidade absortiva: a intensidade e a velocidade com que a empresa busca conhecimentos, bem como a direção desses conhecimentos acumulados (ZAHRA; GEORGE, 2002). A segunda dimensão apontada pelos autores refere-se às rotinas e aos processos que buscam assimilar os conhecimentos adquiridos. Esses processos consistem na análise, processamento, interpretação e compreensão da informação obtida de fontes externas. Essas duas dimensões, aquisição e assimilação, formam o que Zahra e George (2002) conceituam como potencial de capacidade absortiva, o qual explica as capacidades que uma organização tem de buscar e assimilar conhecimentos externos, mas não representa que serão utilizados para gerar inovação nos negócios.

Já a capacidade absortiva realizada ocorre quando uma empresa consegue utilizar o conhecimento adquirido e assimilado para gerar novas oportunidades (ZAHRA; GEORGE, 2002). A capacidade realizada é composta pelas duas últimas dimensões, a transformação e a exploração. A transformação compreende a capacidade de a organização desenvolver e modificar suas rotinas para combinar os conhecimentos adquiridos com os que a empresa já possui. Os autores indicam que essa combinação ocorre com a adição ou exclusão de conhecimentos, bem como com novas formas de interpretar os conhecimentos existentes. Para Zahra e George, "a habilidade de empresas reconhecerem dois conjuntos de informações aparentemente incongruentes, e depois combiná-los para chegar a um novo esquema representa a capacidade de transformação." (2002, p.190, tradução nossa). Aúltima dimensão, completando a capacidade absortiva realizada, é a exploração, que, segundo Zahra e George (2002), configura-se em rotinas destinadas a aplicar nas operações da empresa o conhecimento adquirido, assimilado e transformado. Os autores ressaltam a importância de rotinas que sistematizem a exploração desses conhecimentos, o que gera bons resultados em longo prazo. Entretanto a exploração também pode ocorrer de forma não sistematizada, sem uma rotina específica para atender essa função.

A soma das quatro dimensões da capacidade absortiva forma um recurso intangível fundamental para o desempenho da empresa, permitindo que ela explore novas descobertas e conhecimentos (FLATTEN et al, 2011). As organizações apresentam, no entanto, diferentes ênfases no desenvolvimento de capacidades potenciais e realizadas. Jansen et al (2005) indicam que mecanismos organizacionais associados com capacidades de coordenação impulsionam o potencial de capacidade absortiva, enquanto mecanismos associados com a sociabilização e a conectividade com diversas fontes de conhecimento impulsionam a capacidade realizada.

Dessa forma, a capacidade absortiva também está fortemente fundamentada na aprendizagem organizacional (LANE; LUBATKIN, 1998; JANSEN et al, 2005; FLATTEN et al, 2011). A habilidade das empresas aprenderem e desenvolverem os conhecimentos absorvidos pode balizar a eficiência da capacidade absortiva. De acordo com Harvey et al (2015), as empresas não podem se basear apenas na capacidade individual dos membros desses grupos. Para os autores, a inovação emerge a partir da interação dos membros em comunidades internas e externas, de modo que eles possam adquirir e absorver novos conhecimentos. Esses grupos são denominados pelos autores como comunidades de conhecimento, que, por sua vez, envolvem atividades formais e informais dentro e fora da organização.

Nonaka (1994) propôs um conceito de aprendizagem organizacional que vai além da internalização de conhecimentos. Para o autor, o conhecimento dos indivíduos, das organizações e da sociedade pode ser expandido por meio de um ciclo que ele denomina como espiral de criação de conhecimentos organizacionais. Esse processo envolve o intercâmbio de conhecimentos tácitos e explícitos a partir de quatro modelos: a socialização, a combinação, a externalização e a internalização de conhecimentos. Com esse estudo, Nonaka (1994) advoga uma quebra no paradigma linear de solução de problemas via entrada-processamento-saída, pois, de acordo com o autor, "qualquer organização que lida com um ambiente de mudanças deveria não só processar informação de forma eficiente, mas também criar informação e conhecimento." (NONAKA, 1994. p. 14. Tradução nossa). 
Portanto, de acordo com a perspectiva de Nonaka (1994), a aprendizagem e a geração de conhecimento em uma organização devem ocorrer de forma dinâmica, por meio da transformação de conhecimentos tácitos e explícitos. A ideia de converter informação em conhecimento condiz com a perspectiva que Zahra e George (2002) apresentam para a capacidade absortiva, pois a partir dos processos de aquisição, assimilação, transformação e exploração ocorrem intercâmbios de conhecimentos tácitos e explícitos de diversas fontes. Esses intercâmbios, por sua vez, se dão por meio da sociabilização, combinação, externalização e internalização dos conhecimentos pela organização.

Lane e Lubatkin (1998) propuseram uma relação de capacidade absortiva com a aprendizagem interorganizacional, na qual duas empresas são analogamente comparadas às posições de estudante e professor. Nessa relação, a habilidade de validar, assimilar e aplicar conhecimentos a partir de uma aliança entre organizações depende de três fatores:

(a) o tipo específico de conhecimento oferecido pela empresa professora; (b) a similaridade de práticas de remuneração e estrutura organizacional entre a empresa estudante e a empresa professora; e (c) a familiaridade da empresa estudante com o conjunto de problemas organizacionais da empresa professora. (LANE; LUBATKIN, 1998, p. 462. Tradução nossa)

Para os autores, existem três formas de aprender novos conhecimentos a partir de fontes externas, podendo ocorrer de forma passiva, ativa ou interativa (LANE; LUBATKIN, 1998). A aprendizagem passiva ocorre quando a organização absorve conhecimentos técnicos e gerenciais a partir de fontes observáveis, como advindas da academia ou de consultores. A aprendizagem ativa envolve avaliar os competidores e suas habilidades. Entretanto os autores argumentam que as duas formas de aprendizagem não adicionam o valor de capacidades únicas à organização. De acordo com os autores, isto só é possível na aprendizagem interativa entre duas empresas que realizam uma aliança, permitindo que uma empresa estudante tenha acesso não só aos componentes objetivos e observáveis da empresa professora, mas também aos conhecimentos tácitos. Dessa forma, a aprendizagem compartilhada ganha valor de unicidade, tornando-se menos imitável, o que resulta em vantagem competitiva para as organizações (LANE; LUBATKIN, 1998).

Nooteboom et al (2007) defendem a importância da distância cognitiva no processo de aprendizagem. Os autores afirmam que trabalhadores com os perfis próximos poderão resultar em capacidades de inovação diferentes, pois cada um interpreta o mundo de forma diferente e em consonância com o seu contexto de vida, entretanto salientam que é preciso compartilhar um mínimo de percepções básicas, advindas da cultura organizacional, para que as competências e as motivações estejam alinhadas. Portanto, para um melhor desempenho de aprendizagem, a distância cognitiva não deve ser ampla a ponto de as pessoas não identificarem uma compatibilidade de objetivos, nem tão próxima que as pessoas compartilhem das mesmas experiências, inibindo a oportunidade de gerar novos conhecimentos.

No tocante à indústria criativa, pesquisas também apontam a relação entre a capacidade absortiva e um melhor desempenho em inovação. De acordo com Popescu et al. (2019), essa relação é mediada pela capacidade de integrar e explorar conhecimentos. Santoro, Bresciani e Papa (2020) afirmam que os melhores desempenhos são obtidos por quem estabelece modos informais de colaboração com indústrias culturais e criativas, a partir de fontes de conhecimento híbridas no processo de inovação. Para Sulistyo e Wikaningrum (2019), essa colaboração pode ser impulsionada com a criação de um bom ambiente organizacional, que estimule a vontade de cada indivíduo por compartilhar seus conhecimentos.

No entanto muitos indivíduos que atuam na indústria criativa são profissionais autônomos que prestam serviços temporários para diversas organizações. Diversas empresas do setor criativo operam baseadas em projetos, o que requer a combinação de equipes especializadas de acordo com cada especificidade. Esses trabalhadores freelancers também formam um importante grupo vetor de conhecimentos para uma empresa. Tempest (2009) afirma que os indivíduos que trabalham de forma nômade buscam uma jornada de aprendizagem individual, portanto as relações de aprendizagem ocorrem a partir do conhecimento especializado, conhecimento de contexto e de talentos. Dessa forma, o autor salienta que, em empresas que utilizam redes de trabalhos temporários, a aprendizagem se dá ao expandir a comunidade para fora da organização.

O Quadro 1 apresenta uma síntese dos principais conceitos abordados neste estudo. 
Quadro 1. Síntese da revisão teórica

\begin{tabular}{|c|c|c|}
\hline Conceito & Definição & Autores \\
\hline Capacidade absortiva. & $\begin{array}{l}\text { Capacidade de uma organização reconhecer o valor de novas } \\
\text { informações externas, assimilar e aplicar essas informações para } \\
\text { incrementar sua capacidade de inovar. }\end{array}$ & $\begin{array}{l}\text { Cohen e Levinthal } \\
\text { (1990) }\end{array}$ \\
\hline $\begin{array}{l}\text { Dimensões da capacidade } \\
\text { absortiva: aquisição, } \\
\text { assimilação, transformação } \\
\text { e exploração. }\end{array}$ & $\begin{array}{l}\text { Aquisição: processo em que a empresa identifica e adquire } \\
\text { conhecimento gerado externamente; } \\
\text { Assimilação: processos e rotinas, interpretação e compreensão da } \\
\text { informação obtida; } \\
\text { Transformação: capacidade de a organização desenvolver e modificar } \\
\text { suar rotinas para combinar conhecimentos; } \\
\text { Exploração: rotinas destinadas a aplicar o conhecimento adquirido. }\end{array}$ & $\begin{array}{l}\text { Zahra e George } \\
(2002)\end{array}$ \\
\hline $\begin{array}{l}\text { Aprendizagem } \\
\text { organizacional. }\end{array}$ & $\begin{array}{l}\text { Intercâmbio de conhecimentos tácitos e explícitos a partir de quatro } \\
\text { modelos: a socialização, a combinação, a externalização e a } \\
\text { internalização de conhecimentos. }\end{array}$ & Nonaka (1994) \\
\hline $\begin{array}{l}\text { Aprendizagem } \\
\text { interorganizacional. }\end{array}$ & $\begin{array}{l}\text { Habilidade de validar, assimilar e aplicar conhecimentos a partir de uma } \\
\text { aliança dentro das organizações. }\end{array}$ & $\begin{array}{l}\text { Lane e Lubatkin } \\
\text { (1998) }\end{array}$ \\
\hline $\begin{array}{l}\text { Distância cognitiva } \\
\text { no processo de } \\
\text { aprendizagem. }\end{array}$ & $\begin{array}{l}\text { Proximidade de perfis das pessoas envolvidas no processo de } \\
\text { aprendizagem. }\end{array}$ & $\begin{array}{l}\text { Nooteboom et al } \\
(2007)\end{array}$ \\
\hline
\end{tabular}

Fonte: elaborado pelos autores.

Finalizada a revisão teórica, que contribuiu para a identificação de categorias de análise, no tópico seguinte consta a descrição dos procedimentos metodológicos adotados para a coleta e análise de evidências empíricas.

\section{METODOLOGIA}

A metodologia utilizada consiste em um estudo de caso único em uma empresa de produção de som para audiovisual, neste artigo chamada de empresa X. A pesquisa seguiu as recomendações metodológicas propostas por Yin (2005), de modo que se buscou investigar de forma empírica o fenômeno dentro de seu contexto. A escolha da empresa deu-se pelas características de atuação na indústria criativa e o processo de diversificação de atividades ocorrido, atendendo à lacuna de pesquisa apresentada.

As fontes de evidências utilizadas para triangulação dos dados foram: entrevistas semiestruturadas, observação participante e documentos da empresa. O roteiro das entrevistas baseou-se em 10 questões previamente elaboradas a partir do levantamento teórico, sintetizado no Quadro 1. As perguntas foram submetidas à avaliação de dois experts, sendo observadas e corrigidas as possíveis fragilidades no roteiro de entrevista. Foram entrevistados o diretor da empresa (DE) e a coordenadora administrativa (CA). A escolha se deu pelo envolvimento de ambos no processo de tomada de decisão de novos negócios, bem como pela característica de pequena empresa, com seis colaboradores na época. As entrevistas foram registradas em áudio e, posteriormente, transcritas e analisadas. O Quadro 2 apresenta as perguntas que conduziram as entrevistas semiestruturadas baseadas no Quadro 1, apresentado na seção anterior.

Quadro 2. Roteiro da entrevista semiestruturada

\begin{tabular}{|ll|}
\hline 1. & O que motivou a empresa a optar por ingressar em novo tipo de atividade? \\
\hline 2. & $\begin{array}{l}\text { Que tipo de conhecimento que a empresa já tinha foi levado em consideração na decisão e como auxiliou no desenvolvimento dessa } \\
\text { nova atividade? }\end{array}$ \\
\hline 3. & O que a empresa precisou aprender/ que tipo de competências ela precisou adquirir ou desenvolver para dar conta do novo serviço? \\
\hline 4. & De que forma a empresa desenvolveu essa competência/ adquiriu esse conhecimento? \\
\hline 5. & Como ocorreu o processo de internalização dos conhecimentos necessários para a nova atividade pela equipe interna? \\
\hline 6. & $\begin{array}{l}\text { Como a empresa combinou os novos conhecimentos com as experiências anteriores para desenvolver a nova atividade? Alguns } \\
\text { conhecimentos/processos que a empresa já tinha precisaram ser modificados ou eliminados? Caso positivo, quais? }\end{array}$ \\
\hline 7. & $\begin{array}{l}\text { Quais desses conhecimentos/ dessas competências que a empresa adquiriu/ desenvolveu, a partir de fontes externas, foram } \\
\text { aproveitados em outras atividades que a empresa já vinha realizando? }\end{array}$ \\
\hline 8. & $\begin{array}{l}\text { O que ajudou (em termos de infraestrutura interna da empresa - pessoas/ máquinas/ processos) nesse processo de assimilar o } \\
\text { conhecimento externo, internalizá-lo e aplicá-lo internamente para os serviços da empresa? }\end{array}$ \\
\hline
\end{tabular}

Fonte: elaborado pelos autores. 
Quadro 2. Roteiro da entrevista semiestruturada (continuação)

9. Que tipo de parceria/ colaboração ocorreu no referido processo de aquisição e internalização dos conhecimentos e competências?

10. Como você vê o potencial da empresa para adquirir novos conhecimentos e transformar em oportunidades de negócio? Quais atividades/processos são realizados na empresa para incentivar essa busca por conhecimentos e desenvolvimento de novos modelos de negócio?

Fonte: elaborado pelos autores.

A observação participante foi adotada em virtude da função exercida por um dos pesquisadores na empresa, atuando como coordenador de projetos (CP). De acordo com Gil (2009), a observação participante na forma natural ocorre quando o observador pertence à mesma comunidade ou grupo que investiga. Na condição de coordenador de projetos, o pesquisador esteve diretamente envolvido na absorção e transferência de conhecimentos técnicos e padrões artísticos relacionados ao processo de gravação de dublagens para jogos digitais. Essa posição possibilitou a observação dos procedimentos gerenciais que nortearam a expansão da empresa, bem como a observação de como se deu o compartilhamento dos novos conhecimentos entre os colaboradores fixos e os freelancers contratados.

Os documentos utilizados como fonte de evidências consistem em e-mails e arquivos de vídeo utilizados no período de reorientação estratégica da empresa. O site da empresa também é uma evidência importante, pois passou a apresentar o novo negócio como um dos serviços oferecidos, não estando vinculado com exclusividade ao cliente que impulsionou o processo de diversificação. Após a coleta das evidências, os dados foram analisados de acordo com as recomendações de Gil (2009), procedendo então uma "comparação dos resultados obtidos empiricamente com os que são obtidos dedutivamente de construções teóricas" (GIL, 2009, p. 94). A análise dos dados foi feita de forma qualitativa e as categorias de análise foram definidas com base no referencial teórico sobre a capacidade absortiva. As evidências empíricas foram submetidas à análise de conteúdo, seguindo as recomendações de Bardin (2011).

\section{A EMPRESA X}

A organização escolhida para este estudo está localizada em Porto Alegre, Rio Grande do Sul e atua, desde 2003, no segmento de pós-produção de som para audiovisual. Em 2015, a empresa contava com um quadro fixo de seis colaboradores. Por ter seu serviço baseado em projetos, por vezes contava com freelancers, com uma média de dois profissionais por projeto.

Nos primeiros anos de atividade a empresa atuou nos campos de produção, gravação e mixagem de música, bem como na pós-produção sonora para audiovisual. Nesse último ponto, os serviços se dividem em dois modelos de negócio. O primeiro agrega todos os serviços de pós-produção de som para obras cinematográficas e televisivas. 0 segundo modelo consiste na produção de sons específicos para outras produtoras de som e estúdios que terceirizam parte do serviço. A terceirização ocorre a partir da necessidade de estúdios que não tinham recursos técnicos ou artísticos para gravação de sons de movimentação de personagens e objetos específicos. Essa atividade é conhecida como foley. Portanto, a empresa $X$ fornece foley ${ }^{1}$ para outras empresas que produzem som para audiovisual, alcançando mercados do Rio de Janeiro e São Paulo. Esse formato cria uma dinâmica de mercado em que em determinadas situações as empresas são concorrentes, enquanto em outros momentos colaboram em um mesmo projeto.

Em 2011, o mercado audiovisual brasileiro teve uma grande mudança, a partir da sanção da Lei n. ${ }^{\circ} 12.485$, que fez com que os canais de televisão por assinatura não jornalísticos (conhecidos como canais pagos ou canais de TV fechada) passassem a cumprir uma cota de veiculação diária, em horário nobre, para produções nacionais independentes. Essa lei impulsionou o setor audiovisual para uma migração, na qual produtoras que só trabalhavam com cinema passaram a produzir para televisão, o que também resultou em um crescimento de demanda para a pós-produção sonora.

Contudo, mesmo com esse crescimento, impulsionado pela Lei n. ${ }^{\circ} 12.485^{2}$, as produções cinematográficas e televisivas ainda dependiam muito de recursos provenientes de editais de fomento do setor. Em 2014, a empresa $X$ recebeu uma oportunidade de diversificar sua oferta de serviços e atuar no mercado de dublagens para jogos digitais. Essa oportunidade chegou a partir de uma empresa de fora do Brasil, que buscava fornecedores para gravação de dublagens em português. A possibilidade de um novo campo de atuação levou a empresa a desenvolver uma estratégia de diversificação de atividades, tomando como ponto de partida a expertise técnica e artística no mercado audiovisual. Um processo de testes e trocas de conhecimento e simulação de projeto foi realizado entre as duas empresas. Em 2015, a empresa começou a atuar no novo negócio.

Desde então, ela atua nos dois setores, dividindo recursos, tanto de estrutura bem como de pessoal, para a realização das atividades. Além disto, a empresa passou a buscar profissionais de voz para compor um banco de dubladores, que representam um grupo de mais de 200 profissionais autônomos. Dessa forma, além de gerenciar

1 Foley é uma das camadas sonoras de um programa audiovisual, na qual compreende efeitos sonoros que são criados por um artista de foley, gravando em sincronia com a imagem.

2 Link. Acesso em 31 de Julho de 2016. 
os custos internos e de técnicos freelancers, a empresa passou a lidar com os custos para dubladores. A dinâmica de trabalho resultou em uma nova estrutura de custos e formação de preços para a empresa. Essa nova atividade também trouxe, no entando, uma nova perspectiva de mercado, instaurando relações com novos fornecedores, concorrentes e clientes, impactando em mudanças nos diversos níveis da organização.

Esse cenário, no qual uma empresa de fora do país apresenta uma oportunidade de negócios levando em consideração que a empresa $X$ deveria passar por um processo de aprendizado antes de fornecer os serviços requeridos, evidencia a relevância do estudo de caso sobre a capacidade absortiva no contexto da indústria criativa. Nesse sentido, o presente estudo de caso auxilia na compreensão das circunstâncias em que a capacidade absortiva ocorre em pequenas empresas da indústria criativa.

\section{RESULTADOS E ANÁLISE}

Os resultados, gerados a partir da coleta dos dados, foram agrupados em três seções. Inicialmente, são contempladas as motivações da empresa para buscar o ambiente externo. Posteriormente, são analisadas as dimensões da capacidade abortiva propostas por Zahra e George (2002), as quais são: aquisição, assimilação, transformação e exploração. Por fim, é analisada a relação, proposta por Lane e Lubatkin (1998), entre a capacidade abortiva e a aprendizagem interorganizacional, bem como a distância cognitiva entre os atores dos processos (NOTEBOOM, et al, 2007).

A principal motivação da empresa se relaciona à sua sustentabilidade econômico/financeira. As evidências mostram que a empresa previu a necessidade de diversificação de renda a partir do conhecimento da crise política que se instaurava no país a partir de 2014. Conforme evidenciado na entrevista pelo diretor da empresa:

A partir do momento que em 2014 aconteceu toda aquela turbulência na eleição presidencial, a coisa ficou mais aguda ainda, e a necessidade de diversificar estava muito clara para nós. Então, o que nos levou a buscar outra atividade foi, uma [...] mais do que uma sensação [...] a visão de que [...] a nossa empresa não ia crescer e talvez não conseguisse nem se manter da forma como vinha se a gente não buscasse alguma outra fonte de recurso que não fosse $o$ audiovisual brasileiro. (DE, 2017)

O mercado audiovisual tornava-se limitado por depender de editais de fomento. A empresa desejava entrar no mercado de jogos digitais, motivada pela semelhança artística com as atividades que já vinha desenvolvendo. Conforme o diretor da empresa, "não nos interessava entrar no mercado publicitário. Não nos interessava entrar no mercado fonográfico/musical, mas o mundo dos games é uma coisa que sempre nos interessou" (DE, 2017). Observase que a empresa buscava uma oportunidade de diversificação para atenuar a crise vivida pelo setor audiovisual e que tinha ciência de que haveria a necessidade de novos aprendizados para que a inovação acontecesse. Essa é uma das prerrogativas apontadas por Cohen e Levinthal (1990) e aparece claramente na fala do diretor: "a gente estava pronto para pesquisar o que tivesse que pesquisar".

Assim, quando a oportunidade de atuar com dublagens de jogos digitais ocorreu, a partir da procura realizada por uma empresa estrangeira que buscava fornecedores, a empresa percebeu que era uma alternativa que deveria ser considerada para diversificar a sua atuação.

Quanto aos conhecimentos que a empresa já possuía e que foram aproveitados no desenvolvimento da nova atividade, identificam-se, a partir dos dados, dois elementos centrais: o conhecimento técnico e o conhecimento artístico em áudio. Esse conhecimento foi adquirido por meio de experiências anteriores com dublagens realizadas para produções audiovisuais, servindo como base para o início das novas atividades. De acordo com a coordenadora administrativa da empresa:

O conhecimento que a gente tinha era o foley, a edição de som, gravação de trilha sonora também. Para trabalhar com dublagens acabamos utilizando aquele conhecimento técnico também; a questão do estúdio, dos microfones, o pessoal da parte mais técnica sabia qual sala seria melhor para o cliente poder utilizar. (CA, 2017)

Outro elemento presente, observado na rotina da empresa e destacado pelo diretor, é a experiência em séries de televisão, desde a operação na linha de produção até a organização interna para fazer a entrega no prazo determinado.

A partir dessas motivações iniciais é possível perceber de que forma as dimensões da capacidade abortiva foram contempladas na empresa. A síntese apresentada no Quadro 3 descreve, de forma ampla, os conhecimentos que a empresa precisou adquirir. Constata-se, principalmente, que envolveram questões relacionadas: i) à gestão dos projetos em um contexto de demandas urgentes e entregas diárias do conteúdo produzido; ii) à operação mais rápida do software utilizado; e, iii) à formação de diretores de dublagens. Os dados mostram que parte doconhecimento foi adquirido internamente, de forma empírica, a partir de tentativas e erros, devido à urgência das demandas. 
Em entrevista, a coordenadora administrativa reforça esse argumento: "a gente desenvolveu essa competência trabalhando, no dia a dia, nas gravações, nos agendamentos, nos problemas que surgiam" (CA, 2017).

As evidências documentais mostram que as colaborações interorganizacionais obtiveram influência significativa na aquisição desse conhecimento. O primeiro contato com a empresa estrangeira surgiu em outubro de 2014, quando a empresa $X$ recebeu um e-mail questionando se haveria interesse em fornecer serviços de dublagem, mediante exigências de qualidade técnica e artística, bem como exigências de agilidade e capacidade de gerenciamento. Após esse primeiro contato, a multinacional solicitou testes de equipamentos para a empresa X e, em 2015 , realizou a simulação de um projeto, visando exercitar os processos. Vídeos e manuais com explicações de normas e procedimentos fornecidos pelo cliente no primeiro projeto realizado também serviram como base para a operação que se iniciava.

Entretanto a abertura da empresa, conforme destacado por Cohen e Levinthal (1990), foi fundamental para aproveitar o conhecimento disponibilizado pelo cliente por meio de vídeos, documentos informais e manuais e normas de procedimentos. A distância cognitiva entre os atores envolvidos foi favorável para que o aprendizado ocorresse e houvesse a colaboração interorganizacional (NONAKA, 1994). A aprendizagem ativa, sugerida por Lane e Bubatkin (1998), aconteceu pela forma como as empresas se relacionavam, buscando, de forma coletiva, otimizar processos para alcançar os resultados almejados.

Quadro 3. Síntese dos dados coletados

\begin{tabular}{|c|c|c|}
\hline Dimensões & Conceito central & Evidência na empresa \\
\hline \multirow[t]{2}{*}{ Aquisição } & O conhecimento é identificado. & $\begin{array}{l}\text { Produção; } \\
\text { Casting; } \\
\text { Como operar com múltiplos projetos; } \\
\text { Como realizar pagamentos para os freelancers e dubladores; } \\
\text { Como atender demandas urgentes com a qualidade técnica e artística } \\
\text { exigida; } \\
\text { Relacionamento com clientes fora do Brasil, dificuldade do idioma; } \\
\text { Formação de diretores de dublagem. }\end{array}$ \\
\hline & O conhecimento é adquirido. & $\begin{array}{l}\text { De forma empírica, no dia-a-dia a partir da urgência das entregas; } \\
\text { A partir das informações disponibilizadas pelo cliente em vídeos e } \\
\text { documentos; } \\
\text { Manuais e normas de procedimento encaminhados pelo cliente. }\end{array}$ \\
\hline Assimilação & $\begin{array}{l}\text { Análise, processamento, } \\
\text { interpretação e compreensão } \\
\text { dos conhecimentos. }\end{array}$ & $\begin{array}{l}\text { Reuniões para disseminar o conhecimento; } \\
\text { Ações informais; } \\
\text { Não houve um processo formal; } \\
\text { A partir da urgência das demandas. }\end{array}$ \\
\hline Transformação & Modificação das rotinas. & $\begin{array}{l}\text { A eliminar alguns "pudores artísticos" para viabilizar projetos audiovisuais; } \\
\text { Adaptação dos ambientes; } \\
\text { Organização e método de trabalho; } \\
\text { Trabalhar de forma mais objetiva e otimizada. }\end{array}$ \\
\hline Exploração & $\begin{array}{l}\text { Rotinas para aplicar o } \\
\text { conhecimento transformado. }\end{array}$ & $\begin{array}{l}\text { A empresa está mais aberta para buscar o novo; } \\
\text { Investimento em viagens para conhecer clientes e ampliar a atuação; } \\
\text { Potencial de adaptação e flexibilidade. }\end{array}$ \\
\hline
\end{tabular}

Fonte: dados da pesquisa.

Assim, os dados convergem com a literatura no tocante ao potencial de capacidade absortiva (ZAHRA; GEORGE, 2002) e à relação com a aprendizagem interorganizacional (LANE; LUBATKIN, 1998). Essa convergência faz surgir a hipótese de que, a partir de uma relação de colaboração interorganizacional, o cliente percebeu o potencial de capacidade absortiva da empresa X, optando por iniciar um projeto e compartilhar conhecimentos para que a empresa estudada pudesse exercer as demandas requisitadas. A internalização dos novos conhecimentos foi impulsionada pela elevada urgência das demandas, levando a equipe a realizar pequenas reuniões, muitas vezes de caráter informal, para disseminar os conhecimentos adquiridos. Portanto, verificou-se que, no início das atividades, não houve um treinamento mais formalizado.

Com relação à combinação dos conhecimentos novos com as experiências anteriores, representando a capacidade de transformar (ZAHRA; GEORGE, 2002), bem como o aproveitamento dos novos conhecimentos para as atividades antigas exercidas pela organização, constatou-se que a perda de pudores artísticos oportunizou a realização de processos mais objetivos, bem como a viabilização de projetos com restrições orçamentárias. Nesse ponto, a multidisciplinaridade da equipe surge como evidência fundamental no processo de assimilação e internalização de conhecimento externo. Outro ponto destacado na coleta de dados é a colaboração com funcionários temporários, freelancers, que possibilitaram a aquisição de conhecimentos externos, por vezes advindos de empresas concorrentes, de forma bastante similar ao preconizado por Tempest (2009). 
Com relação à capacidade de explorar os conhecimentos em novas oportunidades de negócio (COHEN; LEVINTHAL, 1990; ZAHRA; GEORGE, 2002), não surgiram outros dados explicitando esse processo, com exceção da oferta do novo serviço anunciado no site da empresa. Nesse ponto, porém, os entrevistados consideram importante a realização de viagens para estreitar o relacionamento com os clientes. Uma evidência que surge a partir da observação participante é o incentivo à aprendizagem, para a qual a empresa possui destinação orçamentária anual, especificamente para financiamento de cursos e congressos para os funcionários.

\section{CONCLUSÃO}

A partir da triangulação das evidências coletadas, bem como do confronto com a teoria levantada, constatase que a capacidade absortiva foi um fator importante para a reorientação estratégica que a organização realizou. Apesar de os resultados apontarem para uma convergência entre a base teórica e o caso estudado, conforme apresentado no Quadro 3, a pesquisa revelou que, em determinados processos, a capacidade absortiva ocorreu de forma empírica e, em alguns momentos, sem uma orientação gerencial mais sistematizada. Essa característica pôde ser revelada pela natureza deste artigo, por ser um estudo de caso na indústria criativa, contribuindo para o preenchimento da lacuna de pesquisa. No entanto essa contribuição revela outras lacunas, que podem servir de inspiração para futuras pesquisas, considerando também as limitações metodológicas deste estudo. Entre as implicações para futuras discussões teóricas e estudos, destacam-se as seguintes questões: i) Em outras empresas do mesmo setor a capacidade absortiva se manifesta de maneira informal e não sistematizada?; ii) quais implicações gerenciais em capacidade absortiva poderiam ser desenvolvidas para orientar empresas da indústria criativa, mais especificamente do audiovisual e de jogos digitais, levando em consideração a dinamicidade do setor e sua operação baseada em projetos?; iii) quais estratégias são utilizadas nas relações de confiança entre empresas e demais atores que participam de projetos audiovisuais?; iv) de que forma empresas com altos índices de utilização de colaboradores temporários podem preservar conhecimentos no ambiente organizacional? v) uma vez que os freelancers circulam por várias empresas do mesmo segmento, formando uma rede informal de compartilhamento de conhecimentos, de que maneira a capacidade absortiva e a aprendizagem organizacional podem contribuir para a gestão estratégica destas organizações? vi) quais características de liderança são fundamentais no gerenciamento de equipes temporárias de artistas, onde a criatividade é fator base para o negócio?

Outro ponto que pode ser destacado consiste na relação interorganizacional entre a empresa $X$ e a empresa cliente, pois ao compartilhar conhecimentos por meio de documentos e até mesmo com a simulação de um projeto, percebe-se que a empresa criou uma relação de confiança e de aposta no potencial de capacidade absortiva da empresa X, mesmo que geograficamente distante. Essa interação mostrou-se fundamental para que o processo de reorientação estratégica se iniciasse de maneira consistente. Esse ponto também pode ser abordado em futuras pesquisas e questionamentos, tais como:

Dada a velocidade com que as mudanças ocorreram, percebe-se que a dinamicidade de eventos desencadeou um movimento espiral na circulação de informações, pois, mediante a contratação de colaboradores freelancers, novos processos de trabalho, bem como suposições da cultura organizacional passaram a ser criados de forma coletiva. Dessa reflexão também surgem novas lacunas a serem preenchidas no campo teórico em relação à empresas da indústria criativa, destacando-se:

Cabe ressaltar que este estudo apresenta limitações em sua natureza metodológica, uma vez que é apresentado um recorte de uma situação para análise. Essa característica torna difícil a afirmação de que os resultados sejam replicáveis a qualquer empresa da indústria criativa, porém, conforme abordado na seção introdutória deste estudo e em levantamento da FIRJAN (2016), são diversas as áreas de atuação que englobam organizações da indústria criativa. Essa diversidade traz características que são peculiares em cada empresa e sua respectiva relação entre geração de valor simbólico/cultural e monetário. Dessa forma, este estudo visa contribuir com a pesquisa e literatura de capacidade absortiva e indústria criativa levando em consideração e apresentando, no caso, as especificidades do segmento de serviços de produção de áudio para audiovisual e jogos digitais.

A partir desses insights, também se salienta a importância de estudos como este na geração de novas discussões no campo teórico, criando uma complementariedade e expansão em relação à pesquisas que buscam validar hipóteses previamente levantadas. Também cabem estudos futuros que possam fornecer uma maior capacidade de generalização para essa teoria na indústria criativa. Por fim, cabe ressaltar que este estudo não tinha como objetivo medir o nível de capacidade absortiva da empresa. Entende-se que a capacidade absortiva é um construto complexo e que dificilmente pode ser medido a partir de uma única experiência, mesmo tendo utilizado múltiplas fontes de dados (FLATTEN et al. 2011). Constata-se, no entanto, a relevância da capacidade absortiva em empresas da indústria criativa, que necessitam de consideráveis doses de flexibilidade para atuação em um ambiente em constante mudança. 


\section{REFERÊNCIAS}

AMABILE, T. A. How to kill creativity. Harvard Business Review, [S. I.], v. 76, n. 5, Sep./Oct., p. 77-87, 1998.

BARDIN, Laurence. Análise de conteúdo. ed. rev. e amp. São Paulo, Edições 70, 2011. 279 p.

BUSS, Caroline Esther; SCHREIBER, Dusan; MACHADO, Raquel Engelman; PINHEIRO, Christiano Max P.; THEIS, Vanessa. Análise da capacidade absortiva no processo criativo. Perspectivas em Gestão \& Conhecimento, João Pessoa, v. 9, n. 3, p. 35-46, 2019.

COHEN, Wesley M.; LEVINTHAL, Daniel A. Absorptive capacity: a new perspective on learning and innovation. Administrative Science Quarterly, [S. I.], v. 35, n. 1, p. 128-152. Mar. 1990.

DUARTE, Roberto Gonzalez; CASTRO, José Márcio de; BORGES, Renata Simões Guimarães. Inefabilidade e socialização na transferência no compartilhamento de conhecimento tácito em países menos desenvolvidos: o caso do Cine Group em Moçambique. Revista de Ciências da Administração, Fortaleza, v. 20, n. 51, p. 55-68, nov. 2018.

FIRJAN. Mapeamento da indústria criativa no Brasil. Rio de Janeiro: Firjan, 2016. Disponível em: http://www.firjan. com.br/EconomiaCriativa/pages/default.aspxf. Acesso em: 13 mar. 2018.

FLATTEN, Tessa C.; ENGELEN, Andreas; ZAHRA, Shaker A.; BRETTEL, Malte. A measure of absorptive capacity: Scale development and validation. European Management Journal, [S. I.], v. 29 p. 98-116, 2011.

FLORIDA, Richard. The rise of the creative class: revisited. New York: Basic Books, 2012.

GIL, Antonio Carlos. Estudo de caso. São Paulo: Atlas, 2009.

GIL, Antonio Carlos. Métodos e técnicas de pesquisa social. 5 ed. São Paulo: Atlas, 1999.

HARTLEY, John; POTTS, Jason, CUNNINGHAM, Stuart; FLEW, Terry; KEANE, Michael; BANKS, John, Key. Concepts in creative industries. London: SAGE, 2013.

HARVEY, Jean-François; COHENDET, Patrick; SIMON, Laurent; BORZILLO, Stefano. Knowing communities in the front end of innovation. Research-Technology Management, [S. I.], v. 58, n. 1, Fev. 2015.

HENDRY, Chris. Understanding and creating whole organizational change through learning theory. Human Relations, [S. I.], v. 49, n. 5, p. 621-641, 1996.

JANSEN, Justin J. P.; VAN DEN BOSCH, Frans A. J.; VOLBERDA, Henk W. Managing potential and realized absorptive capacity: How organizational antecedents matter? Academy of Management Journal, [S. I.], v. 48, n. 6 , p. 999-1015, 2005.

KURNIAWAN, Pebi; HARTATI, Wiwi; QODRIAH, Sari L.; BADAWI, Badawi. From knowledge sharing to quality performance: The role of absorptive capacity, ambidexterity and innovation capability in creative industry. Management Science Letters, [S. I.], v. 10, n. 2, p. 433-442, 2020.

LANE, Peter J.; LUBATKIN, Michael. Relative absorptive capacity and interorganizational learning. Strategic Management Journal, [S. I.], v. 19, p. 461-477, 1998.

MARCONI, Marina de Andrade; LAKATOS, Eva Maria. Fundamentos de metodologia científica. 5. ed. São Paulo: Atlas, 2003.

NONAKA, Ikujiro. A dynamic theory of organizational knowledge creation. Organizational Science. [S. I.], v. 5, n. 1, p. 14-37, 1994.

NOOTEBOOM, Bart; HAVERBEKE, Win Van; DUYSTERS, Geert; GILSING, Victor; OORD, Ad van den. Optimal cognitive distance and absorptive capacity. Research Policy, [S. I.], v. 36, p. 1016-1034, 2007.

POPESCU, Doina I.; CEPTUREANU, Sebastian-Ion; ALEXANDRU, Adriana; CEPTUREANU, Eduard-Gabriel. 
Relationships between knowledge absorptive capacity, innovation performance and information technogoly. Case study: the romanian creative industries SMEs. Studies in Informatics and Control, [S. I.], v. 28, n. 4, p. 463-475, 2019.

SANTORO, Gabriele; BRESCIANI, Stefano; PAPA, Armando. Collaborative modes with cultural and creative industries and innovation performance: The moderating role of heterogeneous sources of knowledge and absorptive capacity. Technovation, [S. I.], v. 92, p. 102040, 2020.

SILVA, Eduardo Robini da; D'ARRIGO, Fernanda Pauletto; FURLAN, Juliana; GANZER, Paula Patrícia; OLEA, Pelayo Munhoz; LARENTIS, Fabiano; DORION, Eric Charles Henri; NODARI, Cristiane Herman; RADAELLI, Adrieli Alves Pereira; PRODANOV, Cleber Cristiano. Capacidade absortiva individual: uma perspectiva com alunos de administração. Espacios, [S. I.], v. 37, n. 1, p. E-2, 2016.

STERNBERG, R. J. The nature of creativity. Creativity Research Journal, [S. I.], v. 18, n. 1, p. 87-98, 2006.

SULISTYO, Heru; WIKANINGRUM, Tri. Fostering absorptive capacity and self-efficacy on knowledge sharing behavior and innovation capability: an empirical research. Complex, intelligent, and software intensive systems. [S. I.]: Springer, p. 981-990, 2019.

TEMPEST, Sue. Learning from the alien: knowledge relationships with temporary workers in network contexts. The International Journal of Human Resource Management, [S. I.], v. 20, n. 4 p. 912-927, 2009.

THROSBY, David. Economics and Culture. Cambridge: Cambridge University Press, 2001.

THROSBY, David. The Economics of Cultural Policy. Cambridge: Cambridge University Press, 2010.

YIN, Robert K. Estudo de caso: planejamento e métodos. Tradução Daniel Grassi. 3. ed. Porto Alegre: Bookman, 2005.

ZAHRA, Shaker A.; GEORGE, Gerard. Absorptive capacity: a review, reconceptualization, and extension. Academy of Management Review, [S. I.], v. 27, n. 2, p. 185-203, 2002.

\section{Contato:}

Chrístian Langaro Vaisz

E-mail: christian.vaisz@gmail.com

Maria Cristina Bohnenberger

E-mail: cristin@feevale.br

Serje Schmidt

E-mail: serje@feevale.br

Dusan Schreiber

E-mail: dusan@feevale.br 